\title{
Osiemnastosekundowa pauza podczas testu pochyleniowego - co dalej?
}

\author{
18-second pause during a tilt test - what next?
}

\author{
Irmina Urbanek, Izabela Poddębska, Paweł Ptaszyński
}

Klinika Elektrokardiologii Katedry Kardiologii Interwencyjnej i Elektrokardiologii Uniwersytetu Medycznego w Łodzi

\section{Streszczenie}

Autorzy przedstawili przypadek młodego mężczyzny, u którego mimo wywiadu omdlenia i istotnej pauzy w trakcie testu pochyleniowego nie zdecydowano o implantacji kardiostymulatora. Pacjent pozostający pod stałą kontrolą ambulatoryjną odnosi korzyści z zastosowanego postępowania zachowawczego. Takie postępowanie pozostaje w zgodzie z aktualnymi wytycznymi, w których kładzie się nacisk na selekcję wąskiej grupy chorych, którzy powinni być kierowani na leczenie inwazyjne (implantacja kardiostymulatora). W najnowszych badaniach podkreśla się coraz większą rolę przedłużonej rejestracji holterowskiej i wszczepialnych rejestratorów zdarzeń. Natomiast brakuje dowodów, na to, że omdlenie kardiodepresyjne w trakcie testu pochyleniowego stanowi jednoznaczne wskazanie do stałej stymulacji serca. Słowa kluczowe: omdlenie, test pochyleniowy, pauza, kardiostymulator

Folia Cardiologica 2017; 12, 5: 479-483

\section{Wstęp}

Pacjenci z zasłabnięciami i powtarzającymi się omdleniami stanowią dość trudną grupę chorych. W zdecydowanej większości proces diagnostyczno-terapeutyczny wymaga współpracy neurologów, kardiologów, a niejednokrotnie również psychiatrów. Niekiedy, mimo intensywnej diagnostyki, nie udaje się zidentyfikować przyczyny zgłaszanych przez chorych dolegliwości, a tym samym lekarze staja w obliczu trudności w wyborze właściwego sposobu terapii.

\section{Opis przypadku}

Mężczyzna, w wieku 34 lat, zgłosił się do poradni kardiologicznej z powodu powtarzających się zasłabnięć. Dotychczas doszło do jednej pełnej utraty przytomności o przebiegu typowym dla omdlenia wazowagalnego (nagły początek, samoistny powrót świadomości, krótki czas trwania), które nastąpiło po około 30-minutowej pionizacji, z objawami przedomdleniowymi. Inne objawy, takie jak zawroty głowy, mroczki przed oczami, ogólne osłabienie, występowały od kilku miesięcy - pojawiały się średnio raz w tygodniu, często były związane ze zmianą pozycji ciała. Dolegliwości znacznie utrudniały codzienne funkcjonowanie młodego mężczyzny, w tym prowadzenie samochodu. Nie występowały w związku z wysiłkiem, nie towarzyszyły im kołatania serca. Wywiad rodzinny w kierunku nagłego zgonu sercowego, kardiomiopatii, zaburzeń automatyzmu i przewodzenia był również negatywny. W badaniu przedmiotowym, poza nadwagą (mężczyzna dotychczas aktywny fizycznie, jednakże od roku z uwagi na zmiane pracy znacznie ograniczył uprawianie sportu), nie obserwowano istotnych odchyleń od normy.

Pacjent przed wizytą w poradni kardiologicznej, w warunkach ambulatoryjnych, został poddany szerokiej diagnostyce obrazowej. Wykonano tomografię komputerową (CT, computed tomography) głowy i klatki piersiowej, ultrasonografię (USG) jamy brzusznej i węzłów chłonnych oraz USG doplerowską naczyń szyjnych, nie stwierdzając 


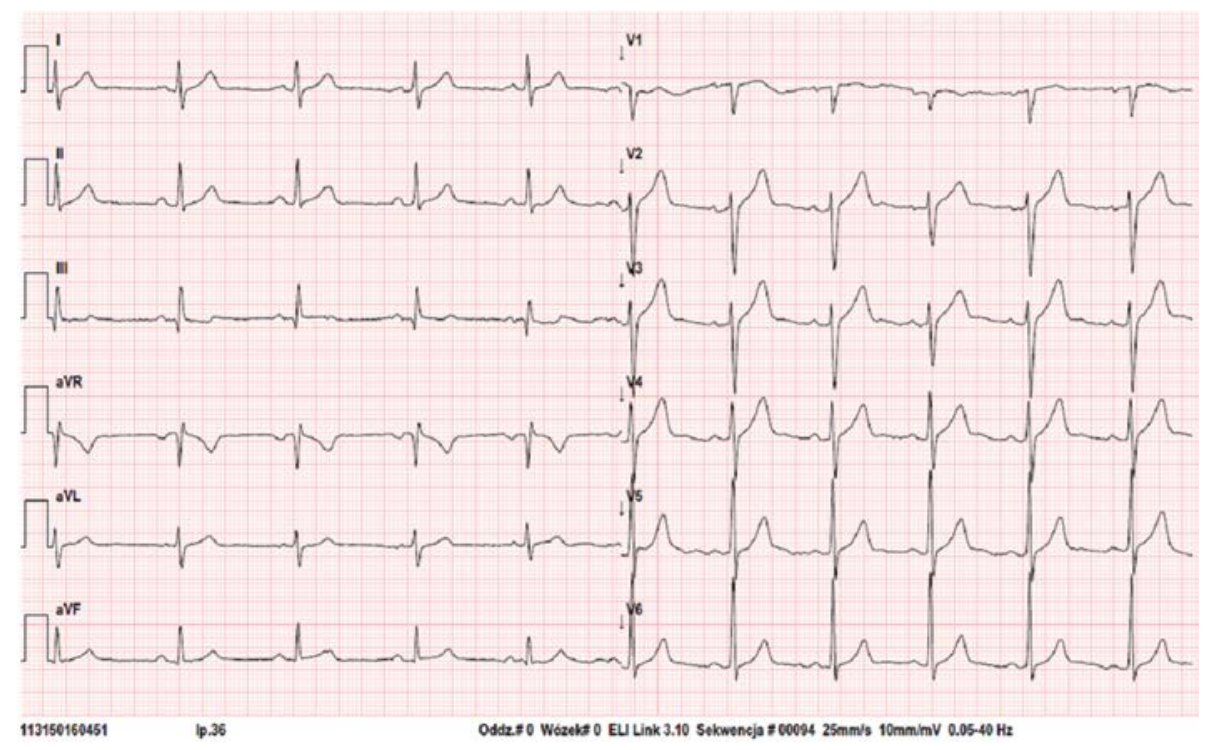

Rycina 1. Badanie elektrokardiograficzne pacjenta

istotnych odchyleń od normy. Chory był również konsultowany neurologicznie. Wówczas uzupełniono diagnostykę o elektroencefalografię (EEG), nie znajdując żadnych nieprawidłowości. W kontrolnych badaniach laboratoryjnych wykluczono stan zapalny, dysfunkcję tarczycy oraz nerek. Tym samym wykluczono neurologiczne i organiczne tło obserwowanych zaburzeń.

Diagnostykę kardiologiczną rozpoczęto od wykonania elektrokardiogramu (EKG), w którym zarejestrowano prawidłowy rytm zatokowy 64/min (ryc. 1). W przezklatkowym badaniu echokardiograficznym i doplerowskim obraz serca i wielkich naczyń był w zakresie normy, aorta piersiowa i tętnica płucna w zakresie widoczności nie wykazywały patologii. Zdecydowano o wykonaniu testu pochyleniowego z jednoczesną 24-godzinną rejestracją EKG metodą Holtera. Badanie przeprowadzono według zgodnego ze standardami protokołu stosowanego w klinice autorów niniejszej pracy: po 15-minutowej fazie wstępnej następuje pionizacja (kąt $60^{\circ}$ ) trwająca do 30 minut, jeśli nadal nie wystąpi omdlenie/objawy przedomdleniowe, jest podana nitrogliceryna podjęzykowo $(0,4 \mu \mathrm{g})$ i następuje dalsza 15-20-minutowa obserwacja. U pacjenta $\mathrm{w}$ trakcie testu, w 4 . minucie po podjęzykowym podaniu nitrogliceryny nastąpiło omdlenie z istotną asystolią i równoczesnym spadkiem ciśnienia tętniczego. Po ustawieniu stołu w pozycji horyzontalnej rozpoczęto masaż pośredni serca, po czym powrócił rytm zatokowy ze średnią częstością 65/min i ciśnieniem tętniczym 120/80 mm Hg, ze spontanicznym powrotem świadomości. Zgodnie z wytycznymi [1] rozpoznano omdlenie wazowagalne o typie kardiodepresyjnym. W wykonanym jednocześnie badaniu Holter EKG w trakcie omdlenia zarejestrowano nagłe zwolnienie akcji serca z 90 do 50-70/ min, a następnie sekwencję zdarzeń elektrokardiograficznych: asystolia/zahamowanie zatokowe 18 sekund (pod koniec pauzy widoczne fale masażu) - pojedyncze pobudzenie zatokowe/węzłowe - pauza 5 sekund - powrót rytmu węzłowego/zatokowego 34-38/min - powrót rytmu zatokowego 60-70/min (ryc. 2). Ponadto w trakcie całego zapisu zarejestrowano rytm zatokowy o częstości 50-119/min w dzień i 40-84/min w nocy, średnia dobowa wynosiła 70/min, bez arytmii przedsionkowej i komorowej, bez zaburzeń przewodzenia przedsionkowo-komorowego. Pomijając okres testu pochyleniowego, w trakcie rejestracji holterowskiej chory nie zgłaszał dolegliwości.

Diagnostykę kardiologiczną uzupełniono wykonując próbę wysiłkową na bieżni ruchomej według protokołu Bruce'a - wynik badania klinicznie i elektrokardiograficznie był ujemny. Badany osiągnął założony limit tętna z prawidłową reakcją presyjną i chronotropową. Wykonano również masaż zatok szyjnych - odpowiedź fizjologiczna. Z uwagi na prawidłowym obraz EKG, brak organicznej choroby serca i wywiadu kołatań, chorego nie zakwalifikowano do badania elektrofizjologicznego.

Pacjentowi zalecono zwiększenie aktywności fizycznej (głównie pływanie, jogging) oraz typowe postępowanie w omdleniach wazowagalnych, czyli zwiększoną podaż soli, płynów i ćwiczenia izometryczne. Zdecydowano o wykonaniu przedłużonej (2-tygodniowej) rejestracji EKG z wykorzystaniem rejestratora koszulkowego firmy Nuubo. W trakcie zapisu również nie rejestrowano odchyleń od normy: rytm zatokowy 45-161/min, średnia zapisu 77/min, jedna pauza 2,1s (ryc. 3). Ponadto, po kilku miesiącach leczenia zachowawczego (jw.) chory zgłosił poprawę samopoczucia oraz redukcję objawów przedomdleniowych. 


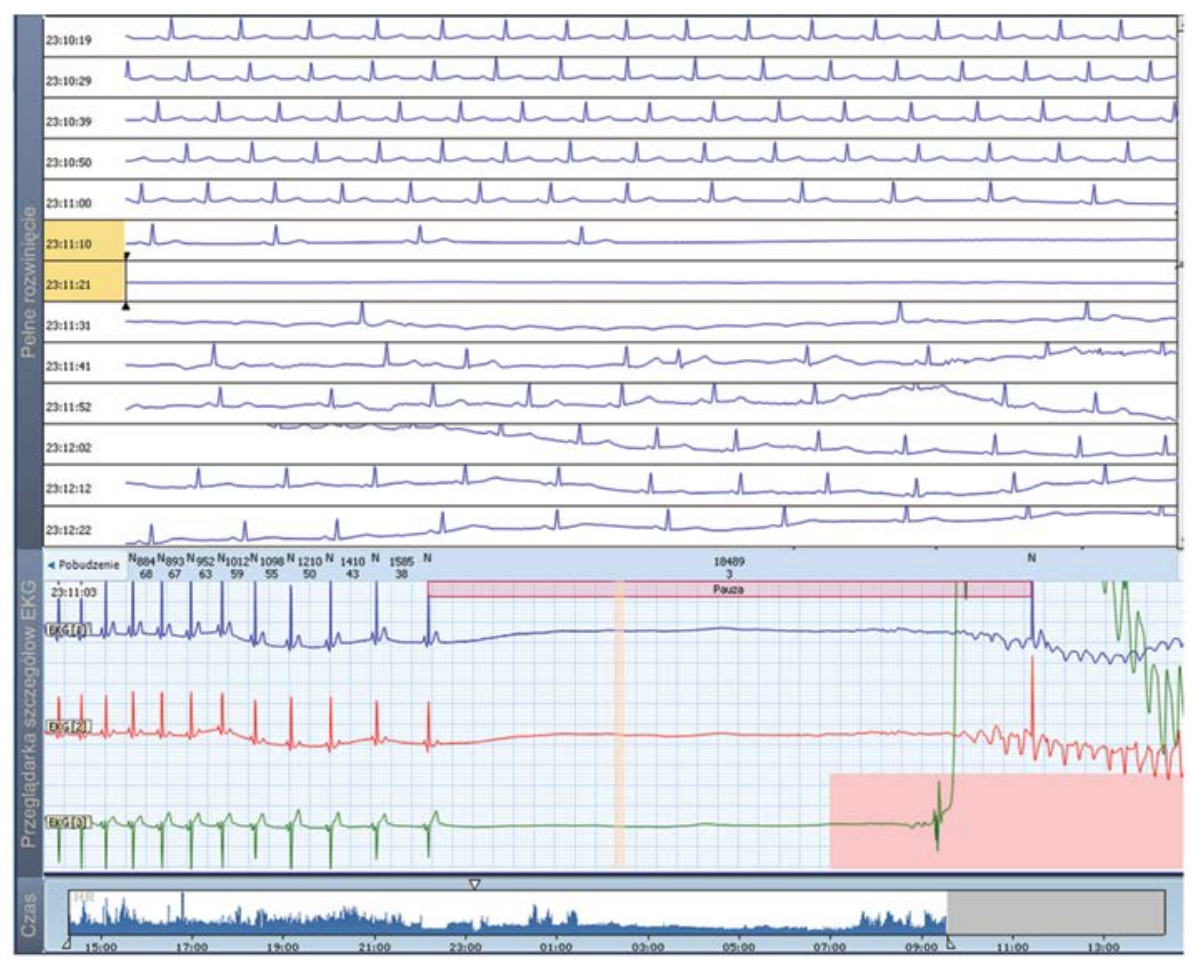

Rycina 2. Rejestracja elektrokardiograficzna metodą Holtera podczas testu pochyleniowego w momencie omdlenia

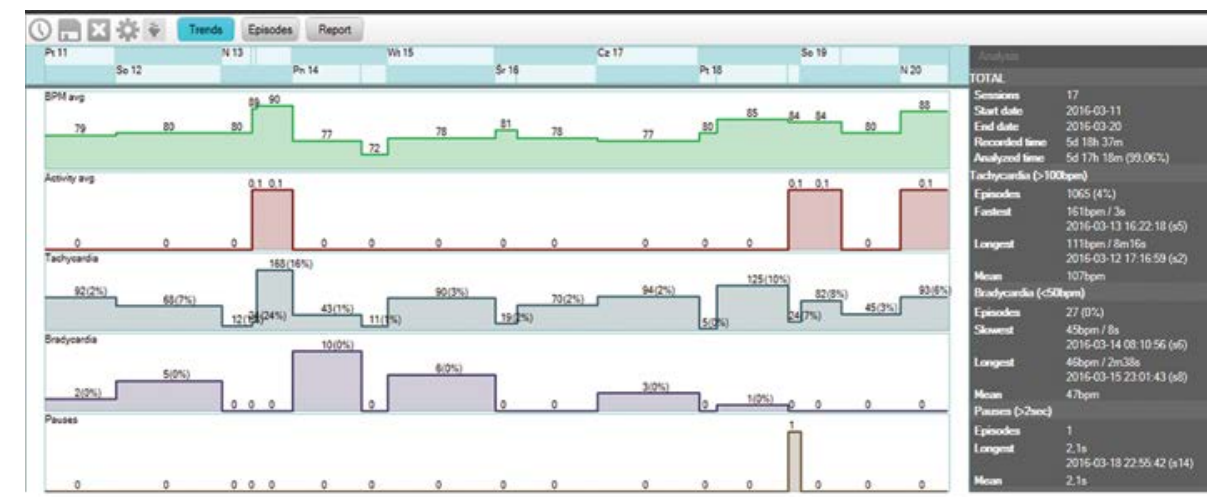

Rycina 3. Trwająca 2 tygodnie rejestracja holterowska (rejestrator koszulkowy firmy Nuubo) - podsumowanie

Opierając się na aktualnych wytycznych i obrazie klinicznym łagodnych omdleń wazowagalnych (dotychczas jedna pełna utrata przytomności z wyraźnymi objawami przedomdlenowymi, dobra reakcja na leczenie zachowawcze), chorego nie zakwalifikowano do implantacji kardiostymulatora na stałe. Obecnie nie zdecydowano również o implantacji wszczepialnego rejestratora zdarzeń (wykorzystano metody nieinwazyjne). Pacjent pozostaje pod opieką ambulatoryjną - w dotychczasowej dwuletniej obserwacji bez pełnych utrat przytomności, z epizodycznymi objawami przedomdleniowymi.

\section{Omówienie}

Omdlenie wazowagalne, które występuje podczas testu pochyleniowego typowo przebiega z hipotonią, a niekiedy również z bradykardią. Implantację kardiostymulatora można rozważać jedynie w sytuacji istotnej dominacji komponenty kardiodepresyjnej. Stymulacja mięśnia sercowego pozostaje bowiem bez wpływu na wazodylatację i związaną z nią hipotensją. Takie stanowisko potwierdzają wyniki dotychczasowych badań, dostarczając sprzecznych danych co do skuteczności stałej stymulacji serca jako formy leczenia 
chorych z omdleniami i dodatnim wynikiem testu pochyleniowego. Ponadto, niejednokrotnie mechanizm omdlenia rejestrowany przez wszczepialne rejestratory zdarzeń (ILR, implantable loop recorder) bywa odmienny od tego, który obserwuje się podczas testu pochyleniowego [2, 3].

Na podstawie wyników badania Third International Study on Syncope of Uncertain Etiology (ISSUE 3; badanie randomizowane, przeprowadzone metodą podwójnie ślepej próby), w którym uczestniczyło 511 pacjentów w wieku $\geq$ 40 lat z nawracającymi omdleniami odruchowymi i wszczepionym ILR oraz jego metaanalizy wykazano, że większą korzyść ze stałej stymulacji uzyskali chorzy z rejestrowanymi wcześniej pauzami w pracy serca, ale z negatywnym wynikiem testu pochyleniowego. Wyniki te sugerują wręcz, że dodatni wynik testu pochyleniowego może być pomocny w selekcji chorych, którzy nie powinny być leczeni za pomocą implantacji kardiostymulatora $[4,5]$.

W większości dokumentów poświęconych omdleniom wazowagalnym podkreślano, że mają one charakter łagodny i zazwyczaj zdarzają się epizodycznie [6]. Biorąc to pod uwage oraz fakt inwazyjnego charakteru zabiegu implantacji kardiostymulatora i związane z nim powikłania, rekomendowano, aby tę formę leczenia dedykować jedynie wyselekcjonowanej grupie chorych [7]. Takie stanowisko zaprezentowano również w najnowszych wytycznych amerykańskiego towarzystwa Heart Rhythm Society (HRS) z 2015 roku [8]. Na podstawie wyników ostatnich badań klinicznych, jako grupę chorych, którzy potencjalnie odniosą największą korzyść ze stałej stymulacji sera wskazano pacjentów o następującej charakterystyce: zdecydowanie po 40. roku życia, z częstymi, nawracającymi omdleniami, z towarzyszącymi urazami i słabo wyrażonymi objawami prodromalnymi, którzy mają udokumentowane dłuższe niż 3-sekundowe pauzy podczas omdlenia klinicznego lub zarejestrowane powyżej 6 sekund bezobjawowe pauzy (klasa Ila, poziom B-R). Podkreślono, że kluczowe znaczenie ma powiązanie objawów klinicznych (omdleń) z rejestrowaną istotną bradykardią lub pauzami. Dlatego, podobnie jak w aktualnych wytycznych dotyczących stymulacji serca i terapii resynchronizującej [1], w powyższych zaleceniach zmierza się w kierunku przedłużonej rejestracji elektrokardiograficznej, w tym implantacji ILR i zaleca ostrożność w podejmowaniu decyzji o implantacji kardiostymulatora na podstawie wyniku testu pochyleniowego.

\section{Konflikt interesów}

Autorzy nie zgłaszają konfliktu interesów.

\section{Abstract}

Authors present a case report of a young man with whom despite to the fainting and significant pauses during a tilt test, implantation of pacemaker was not performed. The patient remains in outpatients care and he seems to refer advantage of the conservative treatment. Above procedure, there is in accordance with current guidelines, which emphasize the selection of a small group of patients among which invasive treatment (pacemaker implantation) should be considered. Recent studies point out an increasing role of prolonged Holter monitoring and implantable events recorders. In contrast, there is no evidence that cardiodepressive syncope during tilt test indicates pacemaker implantation as first-line therapy.

Key words: syncope, tilt test, pause, pacemaker

Folia Cardiologica 2017; 12, 5: 479-483

\section{Piśmiennictwo}

1. Brignole M, Auricchio A, Baron-Esquivias G, et al. European Society of Cardiology (ESC), European Heart Rhythm Association (EHRA). 2013 ESC guidelines on cardiac pacing and cardiac resynchronization therapy: the task force on cardiac pacing and resynchronization therapy of the European Society of Cardiology (ESC). Developed in collaboration with the European Heart Rhythm Association (EHRA). Europace. 2013; 15(8): 1070-1118, doi: 10.1093/europace/eut206, indexed in Pubmed: 23801827.

2. Moya A, Sutton R, Ammirati F, et al. Task Force for the Diagnosis and Management of Syncope, European Society of Cardiology (ESC), European Heart Rhythm Association (EHRA), Heart Failure Association (HFA), Heart Rhythm Society (HRS). Guidelines for the diagnosis and management of syncope (version 2009). Eur Heart J. 2009; 30(21): 2631-2671, doi: 10.1093/eurheartj/ehp298, indexed in Pubmed: 19713422.

3. Brignole M, Sutton R, Menozzi C, et al. International Study on Syncope of Uncertain Etiology 2 (ISSUE 2) Group. Lack of correlation between the responses to tilt testing and adenosine triphosphate test and the mechanism of spontaneous neurally mediated syncope. Eur Heart J. 2006; 27(18): 2232-2239, doi: 10.1093/eurheartj/ehl164, indexed in Pubmed: 16864606.

4. Brignole M, Menozzi C, Moya A, et al. International Study on Syncope of Uncertain Etiology 3 (ISSUE-3) Investigators. Pacemaker therapy in patients with neurally mediated syncope and documented asys- 
tole: Third International Study on Syncope of Uncertain Etiology (ISSUE-3): a randomized trial. Circulation. 2012; 125(21): 2566-2571, doi: 10.1161/CIRCULATIONAHA.111.082313, indexed in Pubmed: 22565936.

5. Brignole M, Donateo P, Tomaino M, et al. International Study on Syncope of Uncertain Etiology 3 (ISSUE-3) Investigators. Benefit of pacemaker therapy in patients with presumed neurally mediated syncope and documented asystole is greater when tilt test is negative: an analysis from the third International Study on Syncope of Uncertain Etiology (ISSUE-3). Circ Arrhythm Electrophysiol. 2014; 7(1): 10-16, doi: 10.1161/CIRCEP.113.001103, indexed in Pubmed: 24336948 .
6. Soteriades ES, Evans JC, Larson MG, et al. Incidence and prognosis of syncope. N Engl J Med. 2002; 347(12): 878-885, doi: 10.1056/ NEJMoa012407, indexed in Pubmed: 12239256.

7. Krediet CT, Parry SW, Jardine DL, et al. The history of diagnosing carotid sinus hypersensitivity: why are the current criteria too sensitive? Europace. 2011; 13(1): 14-22, doi: 10.1093/europace/euq409, indexed in Pubmed: 21088002.

8. Sheldon RS, Grubb BP, Olshansky B, et al. 2015 heart rhythm society expert consensus statement on the diagnosis and treatment of postural tachycardia syndrome, inappropriate sinus tachycardia, and vasovagal syncope. Heart Rhythm. 2015; 12(6): e41-e63, doi: 10.1016/j.hrthm.2015.03.029, indexed in Pubmed: 25980576. 